\begin{tabular}{|l|l|l||}
\hline \multicolumn{2}{|c|}{ PublisherInfo } \\
\hline \hline PublisherName & $:$ & BioMed Central \\
\hline \hline PublisherLocation & $:$ & London \\
\hline \hline PublisherImprintName & $:$ & BioMed Central \\
\hline \hline
\end{tabular}

\title{
Immunonutrition in the critically ill
}

\begin{tabular}{|l|l|l||}
\hline \multicolumn{2}{|c||}{ ArticleInfo } \\
\hline \hline ArticleID & $:$ & 4315 \\
\hline \hline ArticleDOI & $:$ & $10.1186 /$ ccf-2001-73403 \\
\hline \hline ArticleCitationID & $:$ & 73403 \\
\hline \hline ArticleSequenceNumber & $:$ & 26 \\
\hline \hline ArticleCategory & $:$ & Paper Report \\
\hline \hline ArticleFirstPage & $:$ & 1 \\
\hline \hline ArticleLastPage & $:$ & 3 \\
\hline \hline & & RegistrationDate : 2001-12-5 \\
ArticleHistory & $:$ & Received \\
\hline ArticleCopyright & $:$ & Biomed Central Ltd2001-9-20 \\
\hline \hline ArticleGrants & $:$ & \\
\hline \hline ArticleContext & $:$ & 1305455 \\
\hline \hline
\end{tabular}


Michael De Pietro, ${ }^{\text {Affl }}$

Aff1 Christiana Hospital, Wilmington, DE, USA

\section{Keywords}

Enteral nutrition, meta-analysis

\section{Context}

A number of enteral feed formulations have been designed with the hope of enhancing immune function in critically ill patients. A number of studies have been published with conflicting data on the use of such feeds. The authors attempt to address these issues with a meta-analysis of the studies.

\section{Significant findings}

Twenty-two studies - with 2419 patients - were included. Thirteen of these studies involved ICU patients and nine involved postsurgical patients; seventeen studies considered the arginine-rich formulations, Impact (Novartis) and Immuno-AidR. Considering all studies there was no survival benefit shown between patients who received immunonutrition versus standard feeds, both groups having a similar mortality (relative risk $[\mathrm{RR}]=1.1$, confidence interval $[\mathrm{CI}]=0.93-1.31$ ). There was a small decrease in infection risk $(\mathrm{RR}=0.66, \mathrm{CI}=0.54-0.80)$, and length of stay $(-0.63$ days, $\mathrm{CI}=-0.94$ -0.32 days). This benefit was restricted to the high arginine feeds because studies using alternative formulations of immunonutrition actually showed an increase in mortality risk $(\mathrm{RR}=2.13, \mathrm{CI}$ $=1.04-4.21)$. Moreover, in studies of immunonutrition other than high arginine formulations, there was an increase in infection risk and a slight increase in hospital stay compared to controls. These findings were similar when considering only studies of ICU patients. When only high "quality" studies were considered, the use of immunonutrition was associated with a higher risk of mortality than the use of standard enteral feed formulations $(\mathrm{RR}=1.46)$. Paradoxically such studies continued to demonstrate a slightly lower risk of infection with immunonutrition feeds.

\section{Comments}


This meta-analysis suggests that there is no reduction in mortality with the use of specially formulated enteral immunonutrition feeds, versus standard nutritional support. The variability of the studies including differences in the formulations used, populations studied, and design - limits any firm conclusions. Nonetheless, it does suggest that there is little reason to use these expensive forms of nutritional support, and that some formulations may actually cause harm. The formulas containing high amounts of arginine may have a modest benefit in terms of decreasing the risk of infection, and merit further study.

\section{Methods}

A comprehensive literature search using the MEDLINE, EMBASE, CINAHL, and Cochrane Controlled trials databases identified all randomized studies with clear outcome data comparing standard enteral feeds with immunonutrition formulas. Studies had to involve critically ill intensive care or postsurgical patients at risk of becoming critically ill.

\section{Additional information}

\section{References}

1. Heyland DK, Novak F, Drover JW, Jain M, Su X, Suchner U: Should immunonutrition become routine in critically ill patients? A systematic review of the evidence. JAMA. 2001, 286: 944-953. 